World Maritime University

The Maritime Commons: Digital Repository of the World Maritime University

\title{
A key component of continuing professional development in the maritime context
}

\author{
Olga Zavalniuk \\ Kherson State Maritime Academy \\ Volodymyr Nesterenko \\ Kherson State Maritime Academy \\ Inna Zavalniuk \\ Kherson State Maritime Academy \\ Halyna Doshchenko \\ Kherson State Maritime Academy
}

Follow this and additional works at: https://commons.wmu.se/imla2021

Part of the Education Commons

\section{Recommended Citation}

Zavalniuk, O. , Nesterenko, V, , Zavalniuk, I. \& Doshchenko, H. (2021). A key component of continuing professional development in the maritime context. In Pazaver, A., Manuel, M. E., Bolmsten, J., Kitada, M., Bartuseviciene, I. (Eds.), Proceedings of the International Maritime Lecturers' Association. Seas of transition: setting a course for the future (pp. 19-29). World Maritime University. http://dx.doi.org/ 10.21677/imla2021.01

This Paper is brought to you courtesy of Maritime Commons. Open Access items may be downloaded for noncommercial, fair use academic purposes. No items may be hosted on another server or web site without express written permission from the World Maritime University. For more information, please contact library@wmu.se. 
http://dx.doi.org/10.21677/imla2021.01

\title{
A key component of continuing professional development in the maritime context
}

\author{
Olga Zavalniuk MNI \\ Associate Professor, Kherson State Maritime Academy, Kherson, Ukraine, e-mail address \\ olgazavalnjuk82@gmail.com
}

Volodymyr Nesterenko MNI

Captain, Kherson State Maritime Academy, Kherson, Ukraine, e-mail address

nesterenko_mast@mail.ru

\section{Inna Zavalniuk}

Associate Professor, Kherson State Maritime Academy, Kherson, Ukraine, e-mail address zavalnyukinna@gmail.com

\section{Halyna Doshchenko}

Associate Professor, Kherson State Maritime Academy, Kherson, Ukraine, e-mail address hersongala@gmail.com

\begin{abstract}
The maritime industry, one of the world's most influential industries, is developing with a rapid speed. There is, therefore, a special need to find new approaches to prepare students to be ready for the changing realities of modern life. Taking into account generational peculiarities of information perception, new approaches were developed with the aim of building a number of competencies for future marine specialists in order to manage ships safely and efficiently. Ukrainian sailors are said to reflect a high level of training and professional skills, which is considered to be a distinguishing feature. Nevertheless, nowadays Ukrainian seafarers are facing new realities trying to be competitive in the world labour market. Using the approaches created by the authors for the delivery of special courses during navigator training, the key component of continuous professional development was implemented effectively. The authors have evaluated the effectiveness of the approaches by processing the learning outcomes of a focus group. It was found that the tested approaches developed the ability of the students to analyse, evaluate and create, which are crucial in the lifelong learning process to continuously improve professional knowledge, skills and competencies.
\end{abstract}

Keywords: competency based education, creative thinking, critical thinking, lifelong learning, specialized laboratory.

\section{Introduction}

The rapid and dramatic development of the maritime industry, technical modernisation of ships as well as constant increased demands for shipowners in terms of environmental protection and cybersecurity tend to put the lecturers of maritime higher educational institutions under 
constant pressure to find new approaches to the training of future maritime specialists to make them competitive in the labour market. Annually, in Ukraine, about

12000 maritime professionals graduate from maritime educational institutions. At the same time, more than 120000 Ukrainian sailors are already working on internationally owned ships. It should be noted that the Ukrainian sailors are greatly appreciated due to their high level of training and technical skills, which is considered to be one of their distinctive features attributed to the well-established long standing traditions of maritime education in the country. Despite all the efforts and striving to do the best, in the contemporary world, the Ukrainian seafarers are seen to be facing real challenges to remain competitive in the world labour market.

It goes without saying that the maritime industry, as one of the foremost industries in the global economy, has to keep pace by having highly qualified specialists - including deck officers with a certain set of abilities. They are highly likely to embrace the following much-needed characteristics: mental or cognitive flexibility and fast learning, along with adaptation to ongoing qualitative progress in the technical enhancement of ships and success in facing incoming changes and innovations in maritime legislation and related requirements of the International Maritime Organization, classification societies, etc.

According to research data from Gilbert Maturan, Global Training Manager at Teekay (Casey $\&$ Sturgis, 2018), "60\% of learning occurs onboard, through practical, hands-on experience; $30 \%$ takes place through interaction with peers (coaching and mentoring); $10 \%$ comes from formal, short courses taken while ashore". Thus, the very issue of providing specialised base education on a high-level of competence is sure to beneficially contribute to the preparation of future maritime professionals.

The competence-based approach in the primary training of specialists in the maritime industry, in particular navigators, in the Kherson State Maritime Academy (KSMA, Ukraine), has encompassed a wide range of training for decades. Being in the abovementioned environment, the authors of the study have aimed at introducing and mapping innovative approaches to future navigator training to instill the necessity for self-improvement and "never ending learning".

Taking into account the specifics of the goal, empirical research methods, including interviews, questionnaires, rating, self-assessment, observation, experiment, expert assessment and analysis of results have been used. The present scientific research embraces the following directions: analysis and evaluation of the data collected during the educational process for a certain time period and the authors' verified and consolidated experience in conducting professional disciplines for future navigators. In addition, the study method comprises survey and analysis of student term papers, theses and the rating of students.

A Bachelor of Navigation is a specialist according to the requirements of the International STCW Convention, and is able to perform a number of important functions and complex tasks. These functions and tasks require diverse knowledge, skills and abilities, including studying on a constant basis for continuous improvement during the whole course of their professional career. The curriculum of the KSMA is noted to provide a complex combination of special disciplines correlated with the professional competencies' development of a navigator. More specifically, it seems to represent about $80 \%$ of the entire educational program. The main purpose of the research is, based on an example of a professional training course for the bachelor of navigation, "Ship's theory and design", along with the authors' teaching experience, to uncover potential ways to shape the students' lifelong learning in the professional abilities.

\section{Discussion, theoretical or practical implications}


The classic training course, "Ship's theory and design", is considered to be the basic one in the educational program for navigator training. This course is designed to provide the navigator with opportunities to obtain knowledge, skills and abilities relating to the control of stability and strength of the vessel during its functioning. As a result, it tends to lead to the safety enhancement of the vessel in various sailing conditions. Furthermore, it should be noted that the areas of competence of the navigator in accordance with STCW must embrace the following items: "plan and ensure safe loading, stowage, securing, care during voyage and unloading of cargoes" as well as "control trim, stability and stress" (Maturan, 2016). Taking into account a 10 year survey of the educational research laboratory "Ship's theory, design and maritime safety" of the KSMA, 95\% of students enrolled in working practice on a ship were not capable of implementing the theoretical knowledge gained on the shore concerning practical tasks of the ship's cargo plan development. Moreover, it goes without saying that this procedure, while being a routine one, nevertheless reveals, at the same time, the creativity of the navigator in the course of professional activity. Thus, there was an attempt to bridge this gap with the well-documented curriculum for the discipline "Ship's theory and design" in such a way to enhance the practical over the theoretical aspects. Therewith, it had to be regarded as not being in mismatch with the global trends of continuous professional development of a marine specialist, i.e. "Continuing Professional Development (CPD)" (IMO, 2014) as well as revealing its practical and applied properties in the form of a ship's cargo plan development.

A graduate of the maritime educational institution taking their career path is involved in five distinct states of skill acquisition, according to the Dreyfus \& Dreyfus model (IMO, 2014): novice, competence, proficiency, expertise, and mastery. This issue makes us believe the evidence, further highlighting the necessity to form and develop lifelong learning abilities in future navigators.

Thus, a series of innovative approaches to navigator training has been created and carried out by the authors of the research. It is to be emphasised that mastering the competences means that the future maritime officer is passing through several efficient and quite contradictory directions. The essence of these issues is schematically presented in Figure 1,

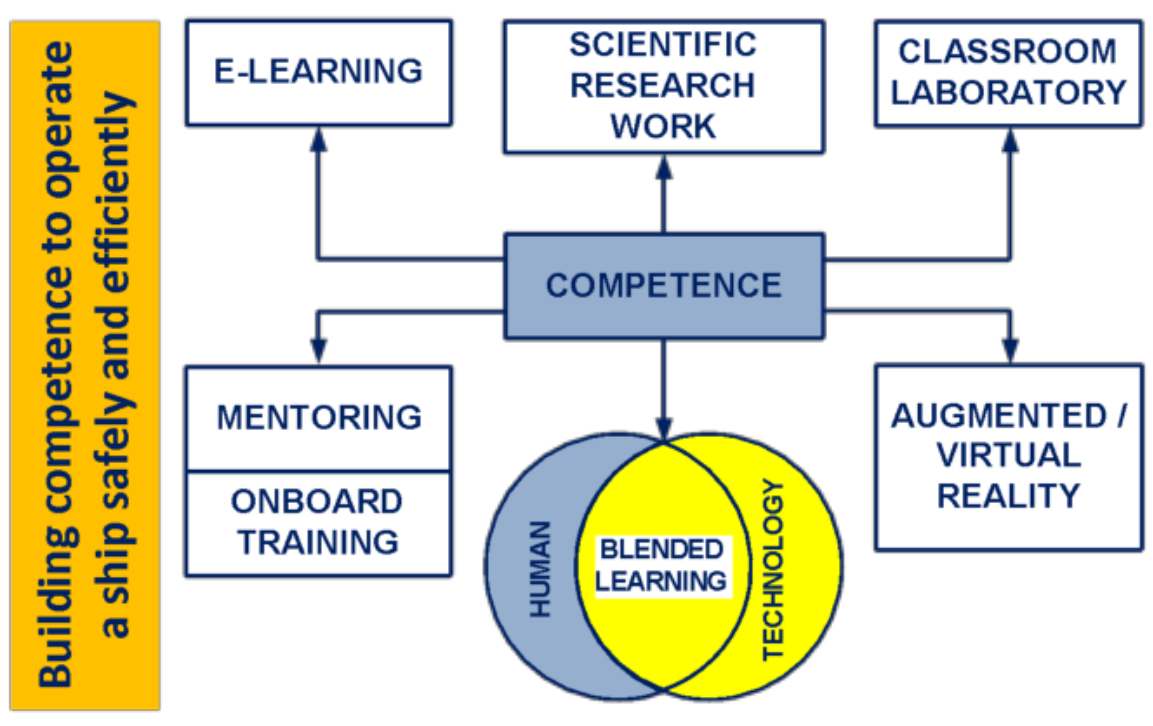

Figure 1. Building competence to operate a ship safely and efficiently. 
Note: reproduced from Chawla, P. (2019). Crewing needs in 2020 and beyond. Seaways, 4, 10-11.

Undoubtedly, such components as e-learning, scientific research work, classroom-laboratory, onboard training, blended learning, and augmented/virtual reality have become extremely important to the formation of a seafarer's sphere of competence.

1. E-learning, blended learning. For the last two years, future maritime specialists' training in a pandemic environment has put increasing pressure on lecturers to find and apply effective innovative approaches to e-learning and blended learning.

In order to study different methods of applying the latest technologies operating in the unique information and educational space, the Academy encouraged the laboratory of innovative technologies to be created. Besides, keeping abreast of these developments empowers pedagogical staff to create electronic, educational and scientific content. 2020 has been spoken about as a year of mixed learning coexisting with remote mode functioning during the quarantine period. In order to facilitate delivery of technical support, methodological guidelines and counselling, lab assistants have been enrolled. Regarding the remote learning process itself, it is worth mentioning that it is provided by the LMS Moodle platform. The LMS Moodle elearning site is noticed to be constantly increasing its performance. For example, in June 2020 the platform was updated to version 3.9.1+. To deal with the a growing need to encourage students and lecturers of KSMA to use modern electronic training technologies (i.e video conferencing, instant messages, chats, exchange of electronic documents) in a much more diverse way, a new electronic system, "Corporate Messenger KSMA - Chat KSMA", was favourably introduced in 2020 during the quarantine period. This process was implemented through the collaboration of the educational and methodological laboratory of innovative technologies and partners. It should be emphasised that the introduction of the abovementioned system was sure to promote widespread use of these training technologies on a corporate scale. Therewith, the system is operating under centralized management with the integrated submission of organizational structures, services, ideology and symbols of KSMA, being successfully integrated into the existing system of information services of the Academy. The system has empowered pedagogical staff to make the most of the learning process organization and its further improvement during the quarantine period caused by the COVID-19 pandemic (remote and mixed forms of training were made to be effectively co-existing) delivering optimization of all facets of its effectivity.

2. Scientific research work. It is vividly seen that the very heart of navigator training seems to comprise the slogan: "It is better to investigate another personnel accident than to have my own". Therefore, students are actively involved in constant message tracking of mass media information concerning severe marine accidents. All these issues might seem to be easily solved due to the availability of the appropriate materials in open press and networks. Therefore, data is being collected and cases are being analyzed; as a result, conclusions are possible to be made nurturing the development of critical thinking among students. In addition, they appear to occupy an active position as researchers of current scientific problems and paradoxes related to the safety of navigation. In this regard, students of senior courses get used to taking part enthusiastically and actively in scientific measurements and experiments on the vessels, making reports in specialized conferences and seminars, along with publishing articles based on the results of their own studies. In this way, creative thinking is encouraged to be beneficially developed. 
3. Classroom-laboratory. During theoretical training, students are used to being located in the auditorium or the specialized learning laboratory, "Ship's theory, design and maritime safety", where the task of forming the scope of the competence of the navigator seems possible. The authors of the study, being involved in conducting the discipline "Ship's theory and design", as a rule, have students face a challenging task with several possible solutions to be applied. Assignments of the following type are highly likely to be targeted to train the imagination and abstract thinking of the future officer at the same time shaping the skill of finding the optimal solution in correspondence to current operating maritime legislation, cargo transportation regulations, recommendations of competent marine practice, and peculiarities of ship building. It goes without saying that the process of competence development is considered to be timeconsuming, including getting gradual benefit from ship building, its operational features and restrictions, learning about the legislative base of shipping and navigation in general as well as particular regulatory documents to be used when planning maritime cargo transportation.

Such conditions for the building of competence have been created during lessons with students, paying special attention to individual work encompassing laboratory and practical class organisation for dealing with cargo plans. Special emphasis is given to the idea that the best form of motivation, according to researchers, is developing students' interest in the proposed material and working with the original publications, and the knowledge required for routine professional life on the fleet. In the above mentioned research laboratory, "Ship's theory, design and maritime safety", original editions of IMO, The NI, P\&I Club (SOLAS, MARPOL, BLU Code, International Grain Code, The Code of Safe Practice for Ships carrying Timber Deck Cargoes, CSC, IS Code, IMDG Code) are used on a regular basis. In addition, the laboratory is equipped with the original Stability Booklets of several real sea vessels, having been purchased by the Academy as "simulators" for the building of navigator competences on the cargo planning of the vessel, in accordance with the requirements of Table A-II/2, STCW. Stability Booklets occupy an essential place in acquiring required knowledge for students in their professional sphere skills.

Accordingly, before the work with Stability Booklets has started, students are to be acquainted with the Intact Stability Code (Chapter 3, paragraph 3.6) as covered in the Stability Booklet, and in particular, the format and the amount of information that is included in the booklet. By comparing the list of information provided in the Code with the content of Stability Booklets, students become clearly aware of the obvious identity of the above mentioned documents under consideration. As a result, a significant conclusion can be reached by them obtaining solid ground about valuable experience of active learning and working with Stability Booklets processes taking place in the laboratory. These issues are believed to contribute to shaping skills highly likely to be useful on the vessel. Exactly this air is gained which allows young people to turn into more business approach-oriented ones towards cargo plan development, escaping from scholasticism and gradual shaping and expansion of their competence sphere i.e. professionalism.

Thus, during the ongoing course of the discipline "Ship's theory and design" (four educational semesters being equal to 2 academic years), availability of aforementioned regulatory documents lets the students consult regulatory acts, codes, and laws, making them use current maritime law and correct documents which ought to be applicable on a regular basis on the vessel.

It is worth mentioning that the curricula of the analyzed discipline has been shaped to be completely in tune with the recommendations of IMO Model Courses 7.01, 7.03. In such 
circumstances Stability Booklets are taken to be used as "simulators" according to the sections of the program. For example, for the "Fresh water allowance" course almost all data is provided for a particular vessel and the students are required to solve a set of tasks focused on the appropriate subject. Likewise, such wholesale "binding" of the curriculum issues to the vessel options has stimulated much student interest. Besides, the multiple uses of Stability Booklets to solve various practical tasks leads to being able to handle the material capacity conjointly with memorizing techniques for using the documents. Subsequently, these items tend to be heading for the development of competence in general.

Spotlighting the targets of finding sustainable approaches to the training of navigators, the newcomers from the initial stages are being challenged to face disorientating tasks including having unsuccessful, dead-end, and indefinite types of solution. For instance, the school's habit of using all data to solve the task gets used to driving them to an undefined answer, dragging out the process of solution achievement and, as a result, causing wasting time etc. Hence, the development of the ability to analyze data allocating the necessary information may seem to point the way towards maturation of useful information retrieval. These are targeted to solving optimization problems coupled with building a foundation for finding a sustainable and favourable approach to any professional challenge.

4. Mentoring. Onboard training. As mentioned above, most of the theoretical knowledge as well as practical skills are targeted to be obtained and updated by the navigators on board of the vessel. $25 \%$ of the total curriculum occurs to be spent in relevant Induction, Shipboard and Industrial practice. Besides, the first sea-going practice experience of students is encouraged to be preceded by educational training on the basis of the KSMA laboratory and simulatory complex. To add, each student is sure to get through the necessary preparation training regarding life safety on board, the use of rescue tools and the vessel safety which are further confirmed by the international certificate, preparing the trainees to be global ready. Moreover, specialised courses involving simulation training, such as "Ship Crane Management", "Fasteners of sea containers", "Security when performing mooring operations", "Rigging" etc. are available to be delivered the same way.

It is to be highlighted that for the sake of meeting the requirements of compliance of the Academy's educational process with the demands of the global maritime industry and employer companies, a training laboratory based on a contemporary vessel of the Marlow Navigation company has been fostered. To be more precise, the laboratory-based model of learning has become possible to be implemented on the vessel "Warnow Jupiter" with an aim to carry out training of the group of students under the guidance of an experienced company coach. At the same time, this very laboratory happens to undertake the tasks of multidimensional targeting such as analysis of highly likely to be reached compliance of theoretical base of KSMA program to the real sea-going experience of students on modern maritime vessels, participation in updating and optimisation of this educational programs and curricula, curricula of special disciplines in particular, as well as training ones.

It is worth mentioning that mentoring is a priority occupying an important position on board the vessel in the process of training. Barely is it possible to name the most consummative way of dealing with striving desire not only to help your classmates, colleagues or future subordinates but simultaneously expand their knowledge and master skills according to the principle: "While teaching I become increasingly aware of the material myself." Thus, it is emphasized by the authors that mentoring is a vital tool for all participants in the educational process, regardless of position, education or age. Being able to share their knowledge and 
experience is by all means to be treated as leverage. In addition to the aforementioned, mentoring creates a friendly and trustworthy environment on board the vessel relieving social isolation in a multinational and multi-religious crew. According to Le Goubin (2017), "Navigating a ship is complex and takes years of experience to master; mentoring on the job is one of the best ways to achieve success".

5. Augmented/Virtual reality. The digital world of virtual reality, referring to computergenerated simulation of reality, seems to be capable of providing a full range of feelings (visual, sound, tactile etc.) Likewise, modern technologies alluding to the mission of enriching our reality without actually existing but with the possibility to be seen and partially even interacted with in real time are considered to be augmented reality. Both technologies are gradually and consistently being introduced into the system of marine officers' preparation. For example, highly responsive virtual reality glasses have been set for research and practical training for special discipline purposes to be attained in the laboratory of innovative technologies. The manufacturer has introduced a series of simulators based on highly engaging virtual reality covering actions that may pose a threat and be problematic if trained in the real world. The unique courses regarding the maturation of rescue boats operation skills, carrying out cargo operations on tankers, steering maintenance, launch of emergency signal rockets and operation of ballast tanks appear to be taken for granted. Virtual reality glasses are certified by Bureau Veritas. There is a multidimensional range of training courses of a specialist/crew available to be worked out concerning life saving appliances, craneker, performing a cargo watch on the tanker, actions on the inspection and availability of the life saving appliances of the vessel (LSA), actions on the inspection and availability of fire fighting equipment of the vessel (FFE), actions to test and prepare the elements of the vessel regulated by the International Convention on Load Lines, action on launch and verification of the emergency diesel generator; actions on maintaining and checking the steering machine, actions for the operation of a foam fire system, actions for the operation of the emergency fire pump, bulker crawlers, mayday signals, the inspection of the hull and its spaces.

Special emphasis is to be given to the eye-catching and brilliant way of material representation. Bright background, 3D bulk parts of a modern vessel, natural light and moving figures of the crew members tend to convey the impression of presence on the ship. Thus, virtual reality is perceived by a person through all sensory organs. Consequently, there is evidence to suggest that an immersion impression makes the students earn professional experience and absorb real emotions. As a rule, the process of mastering the skills of interaction with the three-dimensional environment may be characterised as fervently aspiring to become familiar with it, at the same time figuring out that it is not a game but has endless training capabilities.

\section{The results of the training of navigators on the discipline "Ship's theory and design" in accordance with Bloom's Taxonomy.}

In order to gain a deeper understanding of issues, the authors consider it useful to make the best classification of training goals, acknowledging it as a tool that assists in determining and structuring learning outcomes. On this point, a well-known classification system has been coined by Benjamin Bloom for the cognitive sphere (Ugur et al., 2015; Chandio et al., 2016) is deemed to be the most constructive and favourable one to be applied. The classification represents a hierarchy of learning outcomes defined by the means of verbs. It is a wide-spread and widely-accepted system in an international educational environment. In the cognitive sphere, its essence can be described in the following way. 
1. Remembering is described as the ability to memorize or reproduce facts (terms, specific facts, methods and procedures, basic concepts, rules and principles). 2. Understanding is perceived as the ability to understand and interpret the absorbed material. This means the ability to explain the facts, rules, and principles, for example turn the verbal material into mathematical expression, anticipate or predict the following consequences based on the knowledge gained. 3. Applying is defined as the ability to use the studied material in new situations, for example, to apply ideas and concepts to solve specific tasks. 4. Analysing is illustrated as the ability to split information into components, understand their interconnections and framework structure, detect errors and flaws in the logic of reasoning, understand the difference between facts and consequences and assess the importance of data. 5. Evaluation is explained as the ability to evaluate the importance of material for a particular purpose. 6. Synthesis or Creating is identified as the ability to combine parts together to get the whole air with a new set of properties.

For the sake of getting proper analysis and evaluation of the learning outcomes according to Bloom's taxonomy, the authors agreed upon introducing 50 options of tasks containing 6 questions in each of them. It must be assumed that every question is edited in such a way as not to be in mismatch with one of the six components of the classification. An example of a task is presented in Table 1 .

Table 1.

Contents of Assignment according to Bloom-Anderson Taxonomy Action

\begin{tabular}{|c|c|}
\hline $\begin{array}{l}\text { Bloom- } \\
\text { Anderson } \\
\text { Taxonomy } \\
\text { Action }\end{array}$ & Contents of the assignment \\
\hline $\begin{array}{l}\text { I. } \\
\text { Remembering }\end{array}$ & What is «DWT»? \\
\hline $\begin{array}{l}\text { II. } \\
\text { Understandin } \\
\text { g }\end{array}$ & What kind of condition is to be met for the vessel to be floating? \\
\hline III. Applying & $\begin{array}{l}\text { Calculate the block coefficient for the vessel having length } L p \rho=180 \\
\mathrm{~m} \text {, breadth } 32 \mathrm{~m} \text {, draft } 12 \mathrm{~m} \text {, displacement } 62000 \mathrm{t} \text {. The vessel is located } \\
\text { in salt water. }\end{array}$ \\
\hline IV. Analyzing & $\begin{array}{l}\mathrm{M} / \mathrm{v} \text { «Sunray», } \Delta=38495.1 \mathrm{t}, \mathrm{LCG}=99.12 \mathrm{~m} \text {. Calculate the movement } \\
\text { of } \mathrm{G}\left(\mathrm{GG}_{1}\right) \text { from mass } \mathrm{w}=250 \mathrm{t} \text { is added in № } 1 \text { hold. }\end{array}$ \\
\hline V. Evaluating & $\begin{array}{l}\text { Construct the curves of statical stability for the } \mathrm{m} / \mathrm{v} \text { «Sunray» for } \\
\mathrm{KG}=10.00 \mathrm{~m} \text {; with the draft } \mathrm{d}=8.00 \mathrm{~m} \text { and evaluate of ship stability. }\end{array}$ \\
\hline VI. Creating & The principle and order of cargo plan development. \\
\hline
\end{tabular}

The results of the analysis of the collected data performing the studying process by the navigators of the discipline "Ship's theory and design" in accordance with Bloom's Taxonomy are displayed in Figure 2. It should be added that 55 students from three groups of second year study were chosen to participate in carrying out the experiment granting runtime permission to be tested. The initial findings show that the number of students having coped with the tasks of the first group (I. Remembering) can be named as maximum. Whereas the number of students having managed to fulfil the tasks of the sixth group (VI. Creating) is minimal. These issues notwithstanding, participants were able to thrive in the interpretation of the theoretically studied material and in finding new technical task solutions by means of applying this 
theoretical material in practice. failing at analysis and evaluation being noticed to comprise the least possible to overcome task .

According to the Educational Research Laboratory "Ship's theory, design and maritime safety" more than $50 \%$ of students who are enrolled in certified programs have been taking part in working practice, implementing their practical tasks within the framework of the above mentioned competencies with complete confidence.

\section{Conclusions}

Thus, approaches to teaching one of the professional bachelor's training courses "Ship's theory and design" allows an unprecedented step towards the opportunity of building and shaping a sustainable scope of competence, escaping from surface understanding by the navigator routine basic procedures (loading / unloading of ships, control the landing and stability of the vessel, safety in various weather conditions etc.).
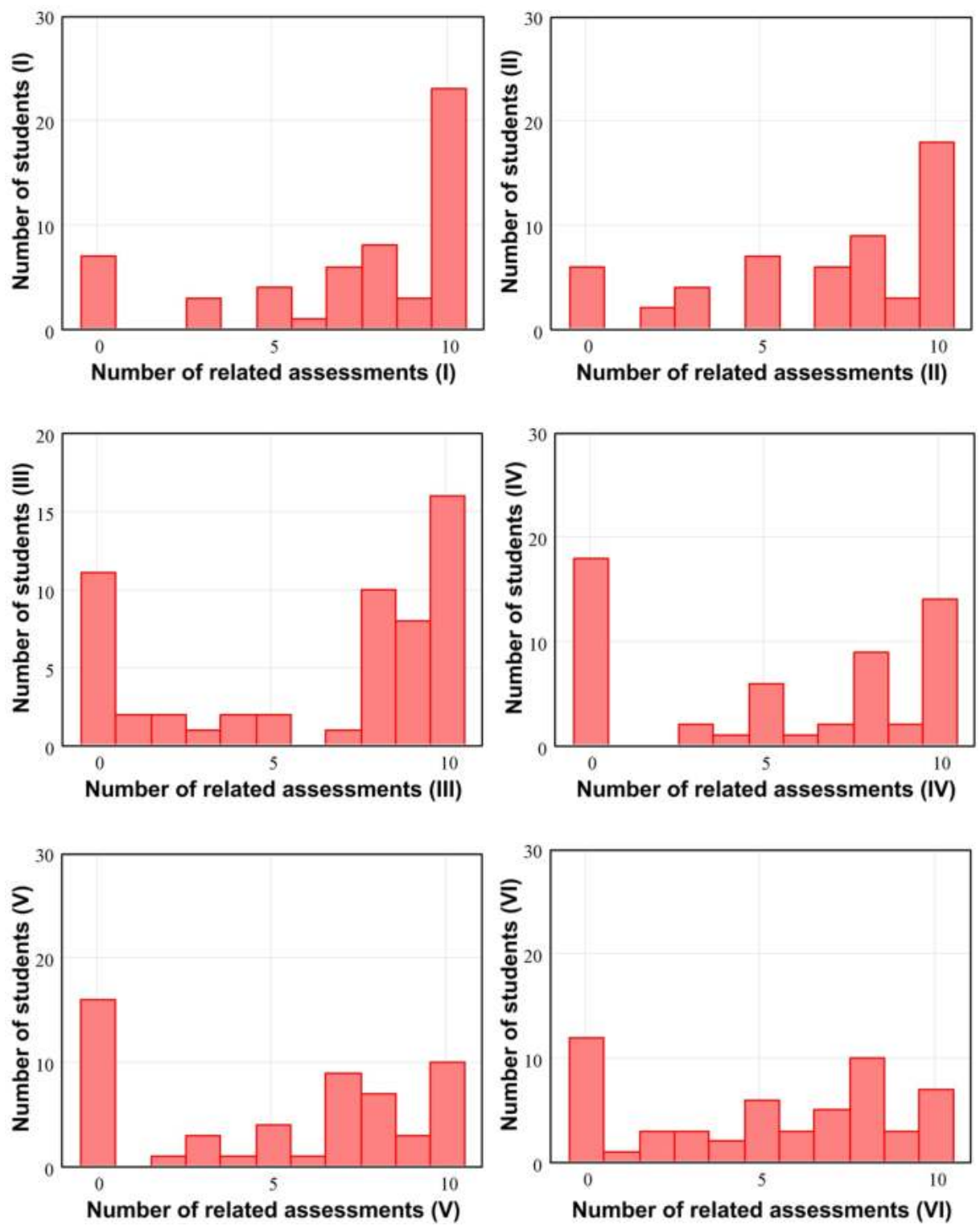


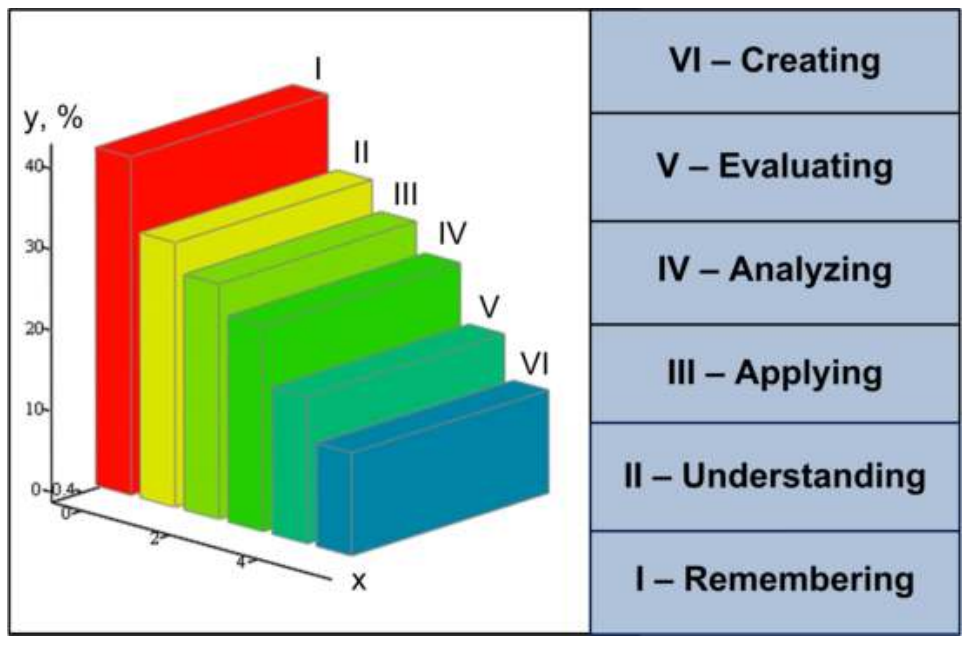

Figure 2. The results of the successful training of navigators on the discipline "Ship's theory and design" in accordance with Bloom's Taxonomy.

As follows, providing the professional reliability foundation of the maritime officer can be considered applicable enough to be embodied. It goes without saying that this very item is being formed gradually, on the long road of consistently replacing each other stages of professionalism. The framework for its functioning is being established in the process of basic special training of a navigator bearing in mind professional adaptation. The aforementioned approaches tend to let young professionals feel self-assured in whatever stressful situations acting professionally and explicitly avoiding minimal mistakes. In addition, it is true to say that having introduced algorithms are highly likely to lay the groundwork for shaping basic students' necessity "Training throughout life", the striving for Continuous Professional Development.

Analysis of the collected data alongside with summing up of positive experience and obtained high incidence of the above research is able to contribute significant benefit into mapping of the educational navigator training program as well as the curricula of other special disciplines. Notwithstanding this fact, the abovementioned area is considered to be a patchy one. So, further suggestions can be made upon conducting the research targeting to assess the quality of students' training delivered on distance mode as well as the effectiveness of the use of Modern Blended Learning Techniques that appeal to generation $Z$ (Cloud Simulation) in the educational process of the Academy.

The development of a student's ability to be studying throughout their whole life, capability to be ready, to be aware of and to use modern technologies, flexibility in professional and social spheres are the only productive ways to shape, empower and facilitate a health conscious individual.

\section{References}

Casey, K., \& Sturgis, C. (2018). Levers and Logic Models: A Framework to Guide Research and Design of High-Quality Competency-Based Education Systems (Competency Works Report). Vienna: iNACOL. (ERIC Document Reproduction Service No. ED590519). 
Chandio, M. T., Pandhiani, S. M., \& Iqbal, R. (2016). Bloom's Taxonomy: Improving Assessment and Teaching-Learning Process. Journal of Education and Educational Development, 3(2), 203-221.

Chawla, P. (2019). Crewing needs in 2020 and beyond. Seaways, 4, 10-11.

Gosling, S. (2015). Continuing Professional Development (CPD): The formal side of lifelong learning. The Navigator, 9, 4-5.

International Convention on Standards of Training, Certification and Watchkeeping for Seafarers (2011). London : IMO. Ashford Press.

International Code on Intact Stability, 2008 (2009). London : IMO

Le Goubin, A. (2017). Learning the Ropes. The Navigator, 15, 4-7.

Maturan, G. (2016). Building on competence. The Navigator, 11, 6-7.

Model Course 7.01 Master and Chief Mate (2014). London : IMO.

Model Course 7.03 Officer in charge of a navigational watch (2014). London : IMO.

.Ugur, H., Stevenson, Constantinescu, Petru-Madalin \& Stevens, Michael J. (2015). SelfAwareness and Personal Growth: Theory and Application of Bloom's Taxonomy. Eurasian Journal of Educational Research, 60, 89-110. 